\title{
Recurrent Classic Hodgkin Lymphoma
}

National Cancer Institute

\section{Source}

National Cancer Institute. Recurrent Classic Hodgkin Lymphoma. NCI Thesaurus. Code C133592.

The reemergence of classic Hodgkin lymphoma after a period of remission. 